\title{
Explaining Outsourcing in Health, Sport and Physical Education
}

Benjamin J. Williams (corresponding author)

School of Education and Professional Studies, Griffith University, Brisbane, Australia

School of Human Movement Studies, The University of Queensland, Brisbane, Australia

E: benjamin.williams@griffith.edu.au

$\mathrm{T}:+61737355760$

Doune Macdonald

School of Human Movement Studies, The University of Queensland, Brisbane, Australia

E: doune@hms.uq.edu.au

T: +61733656769

Word count: 7,148

Revised Manuscript prepared for Sport, Education and Society (April 2014) 


\title{
Explaining Outsourcing in Health, Sport and Physical Education
}

\begin{abstract}
Outsourcing is a complex, controversial and pervasive practice that is increasingly becoming a matter of concern for educational researchers. This article contributes to this literature by examining outsourcing practices related to health, sport and physical education (HSPE). Specifically, it reports data on specialist HPE teachers', principals' and external providers' reasons for participating in outsourcing arrangements. These data were obtained from a collective case study of six schools and the external providers that they outsourced HSPE to over a 12-month period, using semi-structured interviews and overt participant observations. The findings illustrate the ways in which the informants explained their outsourcing practices using a variety of educationally- and organisationally-oriented reasons. Educational value, human resources (e.g., expertise), physical resources (e.g., facilities), and symbolic resources (e.g., status), were reasons for outsourcing HSPE that were commonly cited by principals and specialist HPE teachers. Among external providers, educational value, income generation and promotion/advertising were frequently cited to explain their work with and for schools. These findings illustrate the ways in which outsourcing practices in HSPE articulate with, and are implicated in, broader educational privatisations. They also highlight the boundaries that outsourcing practices trouble or reinforce, such as those marking the purview of markets, membership of the HPE profession, and the constitution of expertise.
\end{abstract}

Key words: outsourcing, physical education, school sport, privatisation, external providers 


\section{Explaining Outsourcing in Health, Sport and Physical Education}

\section{Introduction}

Outsourcing is a complex, often controversial, and increasingly pervasive practice (Lair, 2012), with a history that traces back to the Industrial Revolution and beyond (Domberger, 1998). In recent times, it has been the subject of a large body of writing and research in fields such as business, management, and organisational studies (Mol, 2007). Nevertheless, it has received relatively little attention from educational researchers (Ball, Thrupp, \& Forsey, 2010). This article is intended as a contribution to recent efforts at addressing this lacuna. It does so with a particular interest in outsourcing practices related to health, sport and physical education (HSPE).

Outsourcing is a practice that is characterised by the movement of activities to a market-based organisational location from some other market or non-market organisational location (Lair, 2012). When the relocated activities are educational services, outsourcing is but one form of educational privatisation (Ball, 2007). In this article, we present and analyse teachers', principals', and external providers' explanations of their outsourcing practices in HSPE in Australia. We use this abbreviation to refer to formal schooling practices, both curricular and extra-curricular, focused on physical activity, health and the body (see Tinning, 2010).

The outsourcing of HSPE has recently become an issue of significant interest to health and physical education (HPE) researchers (e.g., Macdonald, 2011; Macdonald, Hay, \& Williams, 2008). Yet, to date, it has remained the focus of few published empirical studies (Williams, Hay, \& Macdonald, 2011). Only a small number of these studies have presented data on teachers', principals' and external providers' reasons for participating in the outsourcing arrangements in which they were engaged. Such data offer an important means of understanding how and why HSPE is being outsourced within a variety of school settings. Notably, only one of these studies has focused directly and explicitly on outsourcing (i.e., Williams et al., 2011). Nevertheless, all of them share some 
degree of concern with forms of market relocation that are consistent with the focus of this study.

Several distinct reasons mark the research literature on teachers', principals' and external providers' explanations of their engagement in HSPE outsourcing practices. Regarding teachers and principals, four such reasons are commonly reported:

- The expertise of the external providers (Ardzejewska, 2009; Evans, 1993; Williams et al., 2011)

- The equipment and facilities of the external providers (Ardzejewska, 2009; Evans, 1993; Williams et al., 2011)

- The value of the learning experiences offered by the external providers to students or teachers (as forms of professional development in the case of the latter) (Ardzejewska, 2009; Evans, 1993; Williams et al., 2011)

- The fulfillment of binding policies and procedures (e.g., health and safety) (Williams et al., 2011).

With respect to external providers, four such motives are commonly described:

- Making money by offering services to schools for which there would be or could be demand (Griggs, 2010)

- Promoting or advertising some related cause or associated organisation (Evans, 1993)

- The value of the learning experiences they offer to students and teachers (Evans, 1993).

The novelty of our contribution concerns a number of related features of the studies summarised above. The first of these features is the division of labour in the schools studied. Only Williams et al. (2011), as part of a larger project connected to the present study, have researched outsourcing in schools that employed specialist HPE teachers. Using questionnaire data, they showed, among other things, that outsourcing was commonplace in the schools studied and was explained by teachers and principals in terms similar to those described above, regardless of this difference in the division of labour. This is an interesting 
finding given how often accessing expertise is cited in the literature as a reason for outsourcing.

Nevertheless, the insight offered by Williams et al.'s (2011) study is partly constrained by the survey methods used, which did not permit these explanations to be explored in detail or triangulated with other data (e.g., observational field notes). Furthermore, because they only surveyed one respondent in each school, Williams et al. may not have captured the full breadth of reasons why outsourcing was occuring. Therefore, our current study is also unique for using methods that collected data from multiple informants within each school.

The last feature that marks the contribution of this study concerns the collection of data from both schools and external providers within the same arrangement. Only one study (i.e., Evans, 1993) has done so previously. However, this data was collected in schools that were not characterised by a specialist division of labour. Accordingly, it offers no insight into the contribution that specialist HPE teachers make to the reasons why schools and external providers participate in outsourcing arrangements.

\section{Method}

The data in this article are drawn from a collective case study (Stake, 1995) of outsourcing in HSPE. The case unit used in this collective case study was the network of relations between a single school and the external providers to which it outsourced HSPE over a 12-month period. Six such cases were studied. These cases were purposively sampled according to six criteria:

1. The school had outsourced HSPE in the previous 12 months

2. The school intended to continue outsourcing HSPE in the future

3. Preliminary investigation indicated that the case would be informative

4. The study consisted of three primary schools and three secondary schools

5. The case was geographically accessible to the researchers

6. The majority of potential informants in a case agreed to participate.

The anonymity of all informants and their organisations has been protected through the use of pseudonyms and by not identifying their schooling sector. The 
latter was a condition imposed by one of the participating school governing bodies.

Through the collective case study, a range of data were collected, including the principals', specialist HPE teachers', and external providers' reasons for participating in HSPE outsourcing arrangements. The first author collected these data over a 12-month period using semi-structured interviews and overt participant observations that generated verbatim interview transcripts and field notes. These data were analysed using a process characterised by:

- Iterative data gathering and analysis

- Ongoing memoing

- Coding

- Ongoing compilation of written accounts

- Conceptual development and literature integration.

A dynamic, non-linear coding strategy was employed that consisted of an initial or open-coding stage, and a focused, integrative and selective coding stage. This coding process was undertaken using a qualitative data analysis software package.

The study took place in Queensland, Australia. In Queensland, specialist HPE teachers are commonly employed in both primary and secondary schools (Ministerial Review Committee for School Sport and Physical Activity, 2007). This position (i.e., the specialist HPE teacher) is officially recognized and relatively long standing (Queensland Department of Public Instruction, 1927; Queensland Industrial Relations Commission, 2010). Occupants of the role are usually the main teachers of HSPE in their schools. The outsourcing of HSPE is typically permitted in Queensland schools at the discretion of the principal or their delegate (e.g., the Head of HPE). Wherever the outsourced activities are conducted, a registered teacher must be present to take overall responsibility, on behalf of the school, for the activities conducted. 


\section{Findings}

The principals, specialist HPE teachers, and external providers that took part in this study explained their outsourcing practices by citing a variety of educationally- and organisationally-oriented reasons. In this section, these reasons are used to organize and present the data collected on the explanations of the specialist HPE teachers, principals and external providers.

Many specialist HPE teachers and principals in this study explained their outsourcing practices through reference to the value or worth of the educational experience afforded by the arrangement. This reason was cited by informants in all six schools and was mentioned by both specialist HPE teachers and principals. Examples included the following:

When I get people in, I guess it depends on the interest from the kids. I guess I'm always trying to diversify and give kids different options. (Bethany Primary School Specialist HPE Teacher, Interview)

External providers are a source of authority. With the Evelyn Fitness Works guys, they're like idols to the kids who are in that course because of the knowledge they have and the work that they do. The kids look up to them and treat them in a different light to your "run-of-the-mill" classroom teacher. (Evelyn Secondary School Head of HPE, Interview)

To be able to bring someone in from outside who is specialized in the area creates more excitement for the students, and they know that they're getting the best knowledge possible. (Dalrymple Secondary School Head of HPE, Interview)

What constituted a meaningful or valuable experience differed from informant to informant. In some instances, particularly in relation to extra-curricular sport, student choice and a diverse range of educational experiences were deemed valuable. In other instances, especially those related to activities within the curriculum, it was particular kinds of knowledge that was considered valuable, or the excitement that it elicited among students. Nevertheless, according to these informants, it was outsourcing that made access to this worthwhile educational experience possible. 
It was also common for the external providers in the study to explain their outsourcing practices in this way. The majority, but not all, of these informants explicitly cited the value of the educational experiences they offered:

So many people are so disconnected in this society and, you know, yoga's one way to help people find that inner balance. So, to help facilitate that in any way is really gratifying. (Francesca Yoga Studio Director, Interview)

We have the belief that when you strip away all the distractions in life all the screens we have these days and all the technology - and you just have the essentials, it's amazing what can happen. We just do pure expeditions. You hike somewhere. You cook your food on a campfire. That's the philosophy and what that can achieve is all the life skills that go with it. You know, developing independence, becoming more selfaware - especially in the group situations and community living. You know, these days our communities are very individualised. It's all about self. We're not about that. It's all about how we work together.

(Francesca Bush Adventure School Centre Manager, Interview)

Well, my main aim is to introduce tennis to children who haven't played, or to improve the games of those who are playing and have played before. The one thing I do want to do is instill enjoyment of the game because it's only through doing that that, you know, children are going to want to play [tennis] and keep playing throughout their life. The fact that you can play tennis with just one other person, or, you know, a small group and you can play into your old age, it sort of stirs me on to give interest to the child and the enjoyment. (Bethany Tennis Academy Head Coach, Interview)

For some external providers, making an educationally worthwhile contribution to young people's lives was a key feature of their explanations of participating in outsourcing arrangements. In these instances, what counted as a worthwhile educational experience was referenced to the external providers' own definitions of "worthwhile". Rarely did these external providers describe their contribution to worthwhile learning experiences in relation to official definitions of educational worth, such as syllabus documents or educational policies. 
Besides these educationally-oriented explanations, participating principals, teachers, and external providers also justified their outsourcing practices on a number of organisational grounds. Among principals and teachers, the human resources of the school were a common reason given, as the following quotes show:

Because it's [i.e., the outsourced self-defence program run at the school] a level of instruction that is superior to what we could deliver and deliver safely. (Dalrymple Secondary School Deputy Principal, Interview) They [i.e., external providers] bring a huge amount of expertise that somebody who is a teacher can't always give. (Evelyn Secondary School Head of HPE, Interview)

Every other school I've been at, the teachers have had to do the swimming coaching. So, what Archibald Aquatic Centre provide, like that's a really good opportunity to provide something that the teachers here couldn't do. (Archibald Primary School Principal, Interview)

For informants such as these, the relevant human resources referred to were people with particular kinds of "expertise," meaning particular kinds of pedagogical knowledge and skills. Explanations of this kind were provided in all six schools and in both curricular and extra-curricular arrangements.

In a similar vein, one of the principals in the study explained how accessing these kinds of expertise could be used strategically from an operational point of view.

Within a cycle of a number of years, you get a number of students who'll come through with a number of different talents and abilities. So, the flexibility is there so that you can then enhance their abilities by bringing in external providers [to use their expertise]. (Francesca Secondary School Principal, Interview)

The implication made by this principal is that some of the outsourcing practices in his school are partly explainable as efforts to access particular kinds of knowledge and skill quickly, and to develop the human resource capacity to be able to respond agilely to changing requirements regarding pedagogical knowledge and skill. This characteristic of outsourcing is referred to in 
organisational studies as its flexibility reservoir function (Semlinger, 1993), and it was only cited in one case school.

Interestingly, when they used explanations that cited expertise in the way described above, informants often spoke about relative differences in pedagogical knowledge and skill, rather than absolute ones. The following quotes illustrate this point well:

They've got good instructors and a great little program there [at Callahan Aquatic Centre]. I'm not an expert at everything and I couldn't run something like that by myself. (Callahan Primary School Specialist HPE Teacher, Field Notes)

I don't think there'd be any one of the school's PE staff that wouldn't say it's best for us to use external providers because the expertise that they can provide in giving our students a really successful and informative lesson is just so valuable to us, and we're happy to. It's not a feeling of, "We're not good enough to teach this, we need someone else." It's, "We can only teach them so much." (Dalrymple Secondary School Head of HPE, Interview)

In other words, these informants tended not to classify themselves or the teachers in their schools as being unknowledgeable or unskilled. Instead, they emphasized the ways in which external providers were more knowledgeable or skilled in particular areas, and/or how outsourcing increased the collective expertise associated with the activities in question. Concerns with collective quantities of expertise were particularly relevant when the outsourced activities were aquatics lessons or outdoor adventure experiences where safety concerns were prominent.

To continue the presentation of human resource-oriented explanations, some informants also explained outsourcing as means of increasing the pedagogical knowledge and skills of themselves and others in their school.

So, not only for our students, but also for our staff, they're [i.e., external providers] a way of letting them see someone who is skilled at what they do - very skilled - and letting them learn from that experience as well. (Francesca Secondary School Head of HPE, Interview) 
It's been really good [i.e., working with the Archibald Aquatic Centre instructors], especially being the only Phys Ed teacher, because you get to bounce other ideas off them, which is really fantastic. Sometimes I even learn something [new]! (Archibald Primary School HPE Specialist Teacher, Interview)

Specialist HPE teachers in two schools cited teacher professional development in this way. In these cases, evidence of teacher learning was discernible. In both instances, the division of labour between external providers and specialist HPE teachers before and during the learning encounter was shared and collaborative. Put differently, these outsourcing arrangements frequently involved external providers and specialist HPE teachers working together to prepare and deliver the learning experience.

The physical resources of the school were the second organisationallyoriented reason cited by informants. Examples of these kinds of explanations included the following:

We go out to Archibald Aquatic Centre because we don't have a pool here, and there's nowhere else to go really. (Archibald Primary School Specialist HPE Teacher, Interview)

I guess with the school there's minimal oval space. That makes it difficult. So, if we can disseminate the kids elsewhere, that's really good. (Bethany Primary School Specialist HPE Teacher, Interview)

It was notable that when physical resources were referenced in these informants' explanations, the physical resources cited were always large infrastructural facilities such as pools or ovals. Seldom were smaller physical resources such as sporting equipment mentioned. Physical resources were cited in five of the six schools. The only school where outsourcing was not explained in this way was a secondary school that employed an external provider to deliver the outsourced program using the school's facilities. Interestingly, despite being well equipped in this regard, this school was characterized by the lowest levels of social, economic and educational advantage, according to Australian Bureau of Statistics (ABS) data, of all the participating schools. 
The symbolic resources of the school were a third, and final, organisationally-grounded reason that was sometimes cited in principals' and teachers' explanations of their outsourcing practices. Symbolic resources were cited in one primary school and two secondary schools, and mentioned by both principals and specialist HPE teachers. Notably, these three schools served communities characterized by relatively high levels of social, economic and educational advantage according to ABS data.

It [the school's outsourcing arrangement with a local martial arts school] brings kudos to the department. Parents see you as providing opportunities that are really worthwhile, because they don't see good touch football teaching, or following the QSA [Queensland Studies Authority] syllabus as necessarily being that exciting. (Dalrymple Secondary School Deputy Principal, Interview)

Parents come and watch the swimming carnivals, so sport's on show. The children are on show. I'm on show. PE is on show. So, it's important that the kids are well prepared for the carnival. We're able to do that by coming here [to the aquatic centre to which the school outsourced its aquatics units]. (Archibald Primary School Specialist HPE Teacher, Field Notes)

Unfortunately, we will always have to do it [i.e., the school's aquatics units]. I think if you stopped it, there'd be a proportion of our parents that would leave the school because it's valued. (Archibald Primary School Principal, Interview)

In some respects, these explanations were related to the educationally-oriented reasons presented above. However, there were also subtle and important differences between them. For example, whereas explanations that referred to the value of the experiences made possible for students, these organisationallyoriented reasons cite the value ascribed to the experience by people removed from the learning encounter, yet ultimately crucial to the continued operation of the school and its programs. In other words, whereas the former were characterized by an intrinsic, educational value being placed on a particular kind of activity, the latter were characterized by an instrumental, organisational value being placed on what the particular kinds of activity symbolised about the school 
or HSPE within it, and how this could be traded on in strategically advantageous ways, like their school's marketing.

Like the principals and teachers, it was also common for external providers to explain their outsourcing practices on organisational grounds. Among these informants, a direct relationship between their involvement in outsourcing arrangements and the financial viability of their organisation was a common feature.

Most of our money comes from the Certificate 3 and Certificate 4 in Fitness. Probably 25 percent of our students are from schools. So, straight away, there's a good incentive for us to run a successful program, otherwise we won't get the job next year. (Evelyn Fitness Works Business Manager, Interview)

I've got 2,000 [school] kids a week and 700 [non-school] after-hours learn to swim kids a week. So, it's [i.e., supplying swimming programs to schools] obviously a big part of our business. (Archibald Aquatic Centre Manager, Interview)

Part of my role has been to really drive the involvement of schools within the program and to get schools involved, with the commercial onus of maximising [our] facility usage [during periods when these facilities are not otherwise being used]. (Bethany Kid Sports Program Manager, Interview)

The informants articulated the important, and in some cases central, financial contribution that the work they do with and for schools makes to the prosperity of their operations as a whole. Explanations like these were given in both primary and secondary school cases and in relation to both curricular and extracurricular activities.

The second organisationally-oriented reason that characterized external providers' explanations of their work with and for schools concerned the indirect contribution it made to their operations.

We like to offer it as something sort of peripheral to the studio. So, it's not essential to the running of the studio, but I find it really beneficial because it gives me balance and opportunities to learn different skills 
and techniques than I would in the studio. (Francesca Yoga Studio Director, Interview)

So, I'd say 35 percent of the school kids we have each week swim here in our after-hours learn to swim or squads, which is great because we see them so much that we build up rapport with them and they rebook their after-hours lessons because of that. That's how you build a business. You've got to look after who looks after you. (Archibald Aquatic Centre Manager, Interview)

The whole idea of the school visits is to promote the University for [potential] future students and the programs we offer. (Dalrymple University Outreach Program Coordinator, Interview)

As before, explanations like these were associated with arrangements in both primary and secondary schools and across both curricular and extra-curricular activities. In these instances, working with and for schools was explained as a way in which external providers could stabilize and develop aspects of their organisation besides the school programs and activities they offered. Typically, these forms of leveraging involved informants making distinctions between core and peripheral activities within their own organisations. Whether or not the informants' work with and for schools was defined as a core or a peripheral dimension of the organisations' operations varied between enterprises depending on a range of factors such as the history, purpose and ambitions of the organisation, as well as the market conditions in which it operated.

A final point concerns the number of reasons cited by each informant. In each of the six cases, informants gave multiple reasons for participating in the outsourcing arrangements in which they were engaged. Furthermore, out of each school and external provider emerged a combination of both educationally- and organisationally-oriented explanations of the outsourcing practices in which they engaged.

\section{Discussion}

One reason for studying outsourcing in schools with specialist HPE teachers is because other authors have linked the practice with the absence of this specialist teacher position (e.g., Lynch, 2005). However, despite the subject specialist 
division of labour in the schools studied here, there was some consistency between the findings presented above and those of previous research. Teacher and principal explanations that referred to human resources (e.g., expertise) and physical resources (e.g., facilities) were common to both this study and previous ones. However, teacher and principal explanations that referred to symbolic resources (e.g., status) were unique to the current study. Additionally, the reasons cited by external providers in this study matched those reported in the literature. To recap, these reasons were educational worth, income generation and promotion/advertising. These similarities and differences highlight a number of issues, and pose a number of questions, about the significance and implications of outsourcing in HSPE. The remainder of this article engages with a selection of these issues and questions.

However, before exploring these matters further, it is necessary to make a brief excursion into methodology. The data collected in this study have been understood, and treated, in a realist mode as both accounts-of-practices and as practices-in-themselves. As accounts-of-practices, the data were understood as descriptions of the participants' outsourcing practices and experiences. As practices-in-themselves, an emphasis was placed on the research context in which these descriptions were collected. When interpreted as practices-inthemselves, it becomes possible to ask interesting questions about what practices and experiences the participants have reported, as well as why and how. Consequently, in the discussion that follows, participants' words are attended to from both these points of view.

One of the first questions raised by these data concerns the nature of those two fundamental economic concepts: supply and demand. Outsourcing is, after all, a commercial relation located within some market. How, then, should the reasons given by the informants be thought about as accounts of the supply of and demand for outsourcing in HSPE? As Callon (2002, p. 209) argues, it is important to avoid two pitfalls in approaching this difficult question:

First, we must avoid thinking that the consumer is being manipulated.

We must avoid assuming that the desire being expressed cannot be imputed at all to the consumer, that instead it passes through the 
consumer because he or she is a member of a certain social class or victim of commercial manipulation. Second, however, we also have to avoid making the assumption that the consumer knows exactly what he or she wants and is the sole author of his or her demand.

In the context of the present study, the first route renders teachers and principals as passive recipients of external providers' offerings, whereas the second renders external providers as passive responders to the pre-existing needs of teachers and principals. According to Callon, both views simplify what is actually far more complex, dynamic and entangled (see also Callon, 1998). Instead, he argues that supply and demand must be understood as both preformed and performed, both structured and emergent, both real and constructed. They are, in other words, generated through a process of joint elaboration between consumers and producers (and researchers as well).

In this spirit, it is possible to turn to a number of the reasons cited by our participants in their explanations, beginning with the notion of educational worth. Treated as accounts-of-practices, the observation that teachers, principals and external providers commonly saw educational worth in the experiences made possible by outsourcing is reassuring in some senses. Lest it be thought that specialist HPE teachers and principals think only of outsourcing as an organisational convenience for the uncommitted, overwhelmed or unprofessional, these data show that the educational worth of the experiences made possible by outsourcing do figure in their curriculum and extra-curriculum making practices. Similarly, to those tempted to suppose that external providers are motivated only by non-educational ends (a sentiment conveyed in some of the literature), these data are a reminder to study schools and external providers symmetrically (Bloor, 1976), exploring one on the same terms as the other.

Yet, perhaps less reassuring in this respect was the lack of stated articulation between external providers' definitions of educational worth and its official definitions as reflected in syllabus and policy documents. Only one external provider discussed his work in these terms. He was unique, however, in that he had completed a HPE degree, worked as a specialist HPE teacher and now 
ran a business that delivered a fitness industry qualification that is sometimes incorporated into the Queensland senior secondary subject, Recreation.

Nevertheless, explanations citing educational value can also be understood as practices-in-themselves in ways that may unsettle these reassurances. For instance, there is undoubtedly a difference between a genuine concern for the wellbeing of young people, and a perceived necessity to communicate such a concern. That said, on the basis of the relationships the first author formed with the informants during the fieldwork experiences, there are good grounds for accepting the sincerity of the sentiments shared about their concern for the educational worth of their services. Regardless of this sincerity, it is analytically noteworthy that principals, teachers and external providers may perceive a need to explain outsourcing in these ways through the joint elaboration that generates both supply and demand and research accounts of these practices.

Given the employment of specialist HPE teachers in these schools, the frequent references by informants to expertise, knowledge and skills is also a finding that is interesting. One way of interpreting this finding is to start from the position that there exists a clearly definable and relatively enduring body of HSPE subject matter and collection of strategies of teaching this content. This body of knowledge would then serve as a reference point for researchers explaining outsourcing as, in part, a product of specialist HPE teachers who are inadequately prepared for their job. Indeed, many have argued in this fashion about HSPE knowledge, although not in discussions of outsourcing (e.g., Siedentop, 2002).

However, there are a number of issues that can be taken with arguments of this kind. While acknowledging that there is some validity to this position, it also fails to acknowledge some important features of expertise in this context (Tinning, 2002). For instance, from a social epistemological standpoint, expertise can be understood as a product of the practices that get labeled "expert," and the practices through which "expert" practices get labeled as such. In short, it can be conceptualised as a product of contestable processes of social construction (see Koppl, 2010). Recall, for example, the way in which informants spoke about 
external providers being idolised by students and of teachers as being "run-ofthe-mill" or about the "kudos" bestowed by parents on an outsourced selfdefence program compared to touch football taught by school teachers. One implication of these comments and others like them was that in the politics of expertise, "the expert" was considered to be "out there" rather than "in here," regardless of what they knew or could do. In other words, it was their location "in the real world" beyond the school that was an important marker of their expertise.

Furthermore, a demand for expertise must also be understood in conjunction with the other features of supply and demand that both pre-exist and emerge out of the interactions between teachers, principals and external providers. Chief among these features were the educational ends being pursued by teachers and principals, as well as the symbolic value of these ends and this expertise. As our data illustrated, the relative superiority of external providers' expertise that influenced demand emerged out of giving students' choice, as well as impressing parents with particular educational experiences or sporting performances. Were these ends not valued or considered relevant, some of the informants may not have problematised their own expertise, or those of their colleagues, in the ways that they did.

Besides the fact that teachers and principals wanted to outsource for a variety of reasons, it should not be overlooked they did so also because the practice is officially permissible. In the introduction, a history of something recognisable as outsourcing that pre-dated the Industrial Revolution was pointed out. Similarly, if one considers the following quote, it might also be tempting to suggest that there is nothing necessarily new about the kinds of interactions we have been studying.

Some of the school teams are assisted by local sporting bodies and major leagues and associations... Assistance such as this is readily provided so long as there is good team-work between the Head Master, Sporting Secretaries, Sportsmaster, Teaching Staff and the Accountant. (Veitch, 1954, p. 17) 
But, if one reflects on the work of those such as Ball (2007), Burch (2009) and Apple (2006) about the ways in which education is being "re-agented" (Jones, 2003) with and by market-based entities, this study points to something peculiarly contemporary and distinctly neoliberal about the institutional context in which our informants work. In particular, it highlights a number of privatisation practices that have been identified as integral to neoliberalisation projects (e.g., Ward \& England, 2007).

Ball (2007), following Hatcher (2000), provides a particularly useful way of comprehending the diversity of educational privatisations associated with neoliberalisation projects globally. This categorisation involves distinguishing between exogenous and endogenous forms of privatisation. Exogenous privatisation is a first-order process that concerns "private companies entering education to take over directly responsibilities, services or programmes" (Ball, 2007, p. 14). By contrast, endogenous privatisation is a second-order process that involves "changes in the behaviour of public sector organisations themselves, where they act as though they were businesses, both in relation to clients and workers, and in dealings with other public sector organisations (Ball, 2007, p. 14).

Using this distinction, the outsourcing of HSPE can be interpreted as a form of exogenous privatisation in which educational services are contracted out. Moreover, as the data presented in this article illustrate, this exogenous form of privatisation coincides and coalesces with a number of endogenous forms of privatisation. For example, informants' references to the symbolic value of the outsourced activities, or the symbolic value of the activities made possible by outsourcing, make visible and explicit these informants' sense of the extent to which they operate in an educational (quasi-) market for parents and students as more or less discerning consumers of an educational service. In this context, activities such as sports carnivals and self-defence lessons become part of entrepreneurial efforts to attract new, and maintain existing, "customers."

Another example of coinciding and coalescing exogenous and endogenous privatisations concerned the policies, procedures and legislation that explicitly permit schools to work with market-based entities in this way (e.g., Department 
of Education Training and Employment, 2011). To be sure, these documents also regulate the practice, but this is not the point. Financial markets are regulated too. Rather, the point is that the movement of educational activities into marketbased locations is permitted in Queensland schools and this is a reason why HSPE is outsourced. This possibility is then acted on, as our informants explained, to generate an income, to promote or advertise some related project or agenda, and/or to provide students with an experience that they believe to be educationally worthwhile.

A third illustration of the ways in which outsourcing is connected to endogenous privatisations is demonstrated in the following quote from an informant:

Increasingly, there's the opportunity to work with schools and that's because of the ... QCE [Queensland Certificate of Education, the State's senior school qualification] where students now get points for Certificate 3 and Certificate 4 [towards the achievement of this qualification], which is a damn good deal. (Evelyn Fitness Works Director, Interview)

In this instance, it is students that the informant believes are getting "a damn good deal." Nonetheless, given the contribution that offering these certificates in and through schools makes to his business operations, one might also suggest that the QCE is "a damn good deal” for him too. For as Ball (2007) explains, exogenous privatisation is, in part, facilitated by endogenous privatisations that organise educational experiences into "commodities" that can be accumulated and segments that can be marketed. This informant has identified an instance of this in the case of the QCE, and has marketed himself quite successfully to teachers, principals, students and parents on this basis.

In closing, this study has sought to better understand the outsourcing of HSPE, as an example of the controversial and wide-ranging privatisations that are increasingly characterising education globally (e.g., Ball, 2012). It has been shown that, in this research context, specialist HPE teachers', principals' and external providers' explanations of their outsourcing cite an array of educational and organisational concerns and considerations. Furthermore, this study has shown how, among the schools studied, these concerns and considerations 
articulate with, and in some instances are implicated in, educational privatisations. Finally, it has done so by treating the data collected as accountsof-practice and as practices-in-themselves, and by conceptualising supply and demand as products of a process of joint elaboration.

Objects and practices that disturb existing boundaries are evocative and "good to think with" because they reveal much about the constitution of the categories that boundaries create and maintain (Turkle, 2005). Among other things, studying these entities can demonstrate the ways in which power is exercised to keep categories apart or mix them together (Bernstein, 2000). Outsourcing in HSPE is such a practice and, accordingly, should continue to be the focus of ongoing scholarly interest and empirical research. This is because in spatial terms, it blurs or troubles a number of boundaries, including:

- The boundary between the inside and the outside of the school as an organisational entity (i.e., what is a school?)

- The boundary between the inside and the outside of the HPE teaching profession (i.e., who is a health and physical educator?)

- The boundary between market and non-market domains within a community (i.e., what ought to be beyond the scope of the market?)

- The boundary between the knowledge and skills of experts and nonexperts (i.e., what is an expert health and physical educator?)

- The boundary between experiences that are educationally valuable and those that are not (i.e., what is a quality health and physical education?)

Interrogations of the processes by which these boundaries are created, maintained or changed through the practices of teachers, principals, external providers, politicians, bureaucrats, and researchers (among others) represent a rich and important vein of critical intellectual work. If the ethical question, "Ought HSPE be outsourced?" is to be answered in a thoughtful, considered and informed way, rigorous empirical studies and robust theoretical analyses of these boundary processes will be crucial. As the articles within this special issue have argued, what was once "an impossible dream" (Tinning, 1992) is increasingly becoming a reality. The time has well and truly come for serious thought to be given to the desirability or the inevitability of this reality. 


\section{References}

Apple, M. W. (2006). Educating the "Right" Way: Markets, Standards, God and Inequality (2nd ed.). New York, NY: Routledge.

Ardzejewska, K. (2009). Managing the Delivery of Subjects in NSW Government Primary School: Using PE "Specialists". (Doctor of Philosophy), Macquarie University, Sydney.

Ball, S. J. (2007). Education plc: Understanding Private Sector Participation in Public Sector Education. New York, NY: Routledge.

Ball, S. J. (2012). Global Education Inc.: New Policy Networks and the Neo-liberal Imaginary. New York, NY: Routledge.

Ball, S. J., Thrupp, M., \& Forsey, M. (2010). Hidden markets: The new educational privatization. British Journal of Sociology of Education, 31(2), 229-241.

Bernstein, B. (2000). Pedagogy, Symbolic Control and Identity: Theory, Research, Critique (Revised ed.). Lanham, MD: Rowman \& Littlefield Publishers.

Bloor, D. (1976). Knowledge and Social Imagery. Boston, MA: Routledge and Kegan Paul.

Burch, P. (2009). Hidden Markets: The New Educational Privatization. New York, NY: Routledge.

Callon, M. (1998). Introduction: The embeddedness of economic markets in economics. In M. Callon (Ed.), The Laws of the Markets (pp. 1-57). Malden, MA: Blackwell Publishing.

Callon, M. (2002). Writing and (re)writing devices as tools for managing complexity. In J. Law \& A. Mol (Eds.), Complexities: Social Studies of Knowledge Practices (pp. 191-217). Durham, NC: Duke University Press.

Department of Education Training and Employment. (2011). FNM-PR-019: State Education Fees, from http://education.qld.gov.au/strategic/eppr/finance/fnmpr019/index.ht $\underline{\mathrm{ml}}$

Domberger, S. (1998). The Contracting Organization: A Strategic Guide to Outsourcing. Oxford, England: Oxford University Press.

Evans, J. (1993). The role of sport development officers in the sport education of teachers. The ACHPER National Journal, Summer, 10-15.

Griggs, G. (2010). For sale - Primary school physical education. $£ 20$ per hour or nearest offer. Education 3-13, 38(1), 39-46.

Hatcher, R. (2000). Power and profit: Business and Education Action Zones. Education Review, 13(1), 71-77.

Jones, K. (2003). Education in Britain: 1944 to Present. Cambridge, England: Polity Press.

Koppl, R. (2010). The social construction of expertise. Society, 47(3), 220-226.

Lair, C. D. (2012). Outsourcing and the contracting of responsibility. Sociological Inquiry, 82(4), 557-577.

Lynch, T. (2005). An Evaluation of School Responses to the Introduction of the Queensland 1999 Health and Physical Education (HPE) Syllabus and Policy Documents in Three Brisbane Catholic Education (BCE) Primary Schools. (Doctor of Education), Australian Catholic University. Retrieved from http://dlibrary.acu.edu.au/digitaltheses/public/adtacuvp96.04092006/02whole.pdf 
Macdonald, D. (2011). Like a fish in water: Physical education policy and practice in the era of neoliberal globalization. Quest, 63(1), 36-45.

Macdonald, D., Hay, P. J., \& Williams, B. J. (2008). Should you buy? Neo-liberalism, neo-HPE, and your neo-job. Physical Educator: Journal of Physical Education New Zealand, 41, 6-13.

Ministerial Review Committee for School Sport and Physical Activity. (2007). Review Report: Future Development of School Sport and Physical Activity Retrieved from http://education.qld.gov.au/schools/healthy/docs/review-futuredevelopment.pdf

Mol, M. J. (2007). Outsourcing: Design, Process, and Performance. Cambridge, England: Oxford University Press.

Queensland Department of Public Instruction. (1927). Annual Report. Brisbane: Queensland Government Printer.

Queensland Industrial Relations Commission. (2010). Department of Education and Training Teachers' Certified Agreement 2010 Retrieved from http://www.qir.qld.gov.au/resources/pdf/certified agreement/cert agre ements/2010/ca2 2010.pdf

Semlinger, K. (1993). Small firms and outsourcing as flexibility reservoirs of large firms. In G. Grabher (Ed.), The Embedded Firm: On the Socioeconomics of Industrial Networks (pp. 161-178). London, England: Routledge.

Siedentop, D. (2002). Content knowledge for physical education. Journal of Teaching in Physical Education, 21(4), 368-377.

Stake, R. E. (1995). The Art of Case Study. Thousand Oaks, CA: Sage Publications.

Tinning, R. (1992). On speeches, dreams, and realities: Physical education in the Year 2001 The ACHPER National Journal, Summer, 24-26.

Tinning, R. (2002). Engaging Siedentopian perspectives on content knowledge for physical education. Journal of Teaching in Physical Education, 21(4), 378-391.

Tinning, R. (2010). Pedagogy and Human Movement: Theory, Practice, Research. New York, NY: Routledge.

Turkle, S. (2005). The Second Self: Computers and the Human Spirit (20th anniversary ed.). Cambridge, MA: The MIT Press.

Veitch, M. (1954). The organisation of winter sport in an Australian junior technical school. Physical Education Journal, 2(1), 16-19.

Ward, K., \& England, K. (2007). Introduction: Reading neoliberalization. In K. England \& K. Ward (Eds.), Neoliberalization: States, Networks, Peoples (pp. 1-22). Malden, MA: Blackwell Publishing.

Williams, B. J., Hay, P. J., \& Macdonald, D. (2011). The outsourcing of health, sport and physical educational work: A state of play. Physical Education and Sport Pedagogy, 16(4), 399-415. 